\title{
РЕЛИГИОЗНЫЕ ЦЕННОСТИ В ДУХОВНОЙ КУЛЬТУРЕ СОВРЕМЕННОЙ СТУДЕНЧЕСКОЙ МОЛОДЕЖИ
}

\author{
П. П. КРУСЬ
}

Брестский государственный университет им. А. С. Пушкина, г. Брест, Беларусь

Религия всегда составляла и продолжает составлять значительную часть культуры человеческого общества. Вероятно, как считают многие мыслители, религиозное сознание будет сопровождать социальную деятельность всегда. В самом деле, только полное исчерпывающее знание обо всем могло бы ослабить роль и значение веры, но такое знание в постоянно развивающемся и изменяющемся мире совершенно невозможно и непредставимо.

Люди должны смириться с тем очевидным фактом, что им всегда предстоит иметь дело с дефицитом рациональных и опытных знаний для принятия различных, в том числе жизненно важных решений. Этот непреложный и очевидный факт ни в коем случае не может препятствовать извечному стремлению человека к истине и ее обоснованию. Скорее наоборот, древний сократовский принцип: «я знаю, что ничего не знаю...» остается действенным средством глубокого познания мира и своего места в нем. И не только собственно познания, он выступает реальным фактором ннравственного, собственно человеческого отношения к действительности.

Как форма общественного сознания религия пронизывает все сферы общественной деятельности на каждом этапе ее развития. Тем не менее, в каждой конкретной социальной системе религиозное сознание приобретает свое особенное преломление, в котором культура отражается самым неповторимым образом.

Современное общество представляет собой сложную партию взаимоотношений различных форм общественного сознания, в которой религия по-прежнему играет одну из важнейших ролей. Обычно констатируют особую приверженность религиозным ценностям представителей зрелого и пожилого возраста. Применительно к ряду стран постсоветского пространства, куда входит и Беларусь, этот тезис требует серьезной корректировки. Дело в том, что люди преклонных лет в этих государствах рождались и провели свою молодость в период активной государственной атеистической пропаганды, которая, безусловно, принесла заметные плоды. Речь идет не только о потере культовых традиций и обычаев. Сама структура мировоззрения подверглась существенным изменениям, и роль религиозных ценностей в ней была серьезно снижена.

Социологические опросы, например, показывают, что значительная часть 70-летних пенсионеров не отличается крепкими знаниями религиозной жизни от молодежи, а в некоторых случаях даже ей уступают.

Уже первые попытки проанализировать динамику ценностных ориентаций студенческой молодежи наталкиваются на заметные теоретические и методологические препятствия. К ним, в частности, относится проблема интерпретации данных социологических опросов. Так, например, подавляющая часть студентов отмечает свое, в целом, положительное отношение к религии вообще и вере, в частности. Вместе с тем, значительная часть этих же респондентов уверенно заявляет также и о своей вере в приметы и прочие формы проявления суеверий. Данное положение совершенно противоречит первому ответу и если не отменяет его вообще, то значительно изменяет содержание и делает невозможной его однозначную оценку. 
Следует отметить, что прямые ответы на поставленные социологами вопросы не образуют, к сожалению, достаточно ясной и целостной картины религиозных предпочтений молодежи. Для прояснения ситуации приходится учитывать довольно сложный механизм взаимодействия различных мировоззренческих факторов. Это по-настоящему комплексная проблема, требующая выработки соответствующей методологической базы и соответствующего понятийного аппарата.

Наличные социологические данные на данный момент не позволяют утверждать о некой прямой линии роста религиозности в молодежной среде. Действительно, многие представители этой части населения знают и уважают религиозные ценности, но обращаются к ним чаще всего периодически, либо в состоянии переживания острых кризисных моментов, либо в соответствии с обстоятельствами народных или семейных традиций. При этом глубокие знания о сущности культовых и некультовых действиях встречаются довольно редко.

Вместе с тем, студенты осознают ту высокую роль религии, в нашем случае христианства, которую она играла в качестве нравственного фактора воспитания. Христианская культура развивала дух милосердия, который органично соединился с идеей интернационального единства, что явно способствовало, в целом, мирному сосуществованию различных народов на территории нашего государства. Отсюда и соответствующее правосознание, что чрезвычайно тесно срослось с нравственностью. Здесь и прочный фундамент межконфессиональной и поликультурной толерантности, которая всегда выступает одним из заметных признаков менталитета нашего народа.

Однако, сам механизм взаимовлияния различных духовных процессов на мировоззрение человека и общества весьма сложен, многообразен и противоречив, что требует отдельного тщательного научного исследования

На самом деле мы здесь встречаемся с довольно сложной мозаичной картиной ценностных предпочтений. В этой картине легко обнаруживаются и характерные признаки мифологического мировоззрения, вступающего во взаимодействие с элементами религиозного, научного и обыденного сознания. Это взаимодействие далеко не всегда отличается гармоничностью и бесконфликтностью, особенно если речь идет о молодежи. Именно механизм взаимодействия важнейших структурных элементов мировоззрения является самым сложным и значимым объектом междисциплинарного комплексного изучения современной науки.

В этом отношении философия может сыграть свою важную роль - стать методологическим интегратором указанного спектра научного поиска. Именно в философии давно практикуется методологический анализ проблемы человека в контексте его мировоззрения. Выявлены структура и сущность интеграции различных научных дисциплин, определены характер и значение комплексного подхода как наиболее действенного общенаучного метода решения теоретических и практических проблем человека и общества, раскрыта сущность взаимодействия философских концепций и других исторических форм мировоззрения: мифологии и религии.

Следует признать, до сих пор нет полного единства по вопросу о методологических основаниях феномена интеграции научных подходов к рассматриваемой проблеме. В литературе встречаются самые разнообразные представления об интеграции научного познания: от отождествления этого понятия с термином «синтез» до понимания интеграции как совокупности согласованных исследовательских программ. В любом случае междисциплинарная интеграция представляется сложной, но требующей своего немедленного решения методологической задачей.

Среди известных способов организации интегративного знания комплексный подход представляется нам наиболее соответствующим для изучения динамических процессов в мировоззрении человека и общества. Более того, сам человек как главный объект 
комплексного подхода был впервые сформулирован именно в связи с осознанием необходимости поиска более тесного механизма взаимодействия между различными, часто весьма разрозненными, исследованиями. Задача заключается в разработке такой методологии, которая бы позволила сохранить целостный системный взгляд на человека и его фундаментальные ценности, среди которых религиозные занимают по-прежнему достаточно значимое место.

Комплексность предполагает тщательное исследование не только всей грандиозной системы «человек-общество», но и тончайших механизмов взаимовлияния духовных процессов, формирующих внутренний мир в его исторической динамике. Только на этом пути можно преодолеть односторонность и заблуждения во взглядах на мировоззрение и ценностный мир современной студенческой молодежи.

Результаты, получаемые в результате такого подхода, убедительно демонстрируют приверженность молодых людей к идеалам высокой духовности и гуманизма. Очевидно их стремление не к противопоставлению, а к гармоническому сочетанию светских и религиозных источников формирования мировоззрения. Подобное стремление не может не вселять оптимизм на взгляды о будущем развитии современной цивилизации.

В статье рассматриваются религиозные ценности в духовной культуре современной молодежи. Результаты социологических исследований свидетельствуют о приверженности значительной части молодежи основным религиозным ценностям. Указаны также некоторые теоретические и методологические проблемы их изучения. Утверждается тезис о значимости комплексного подхода при рассмотрении мировоззрения и ценностных ориентаций молодежи.

The article examines religious values in the spiritual culture of modern youth. The results of sociological studies indicate the adherence of a significant part of young people to basic religious values. Some theoretical and methodological problems of their study are also indicated. The thesis about the importance of an integrated approach when considering the worldview and value orientations of youth is approved. 